\title{
ANTROPOLOGÍA DE LAS PRÁCTICAS COTIDIANAS: MICHEL DE CERTEAU
}

\author{
ANTHROPOLOGY OF CULTURAL PRACTICES: MICHEL DE CERTEAU
}

\author{
Rossana Cassigoli Salamon ${ }^{1}$
}

\begin{abstract}
Este artículo explora el significado y relevancia de la teoría de las prácticas cotidianas en la obra del antropólogo e historiador jesuita Michel de Certeau. Asimismo, consigna las fuentes más relevantes en las cuales abreva su trabajo, explicitadas en sus textos: Kant, Marx, Freud, Wittgenstein y Lefebvre, sin pasar por alto las contribuciones de Foucault y Bourdieu con las cuales establece un diálogo fructífero. De Certeau emplaza, como urgencia antropológica y política, la reflexión de las prácticas humanas de la habitabilidad y la convivencia. Un elemento trascendental y estratégico de pertenencia radicaría en las prácticas; "maneras de hacer" tradicionales y propias, mediante las cuales "lo colectivo" -que encarna un valor primigenio de la especie humana- permanecería irreducible ante el embate homogeneizador de la civilización moderna. Las prácticas cotidianas permanecerían esparcidas como "memorias", combinando rastros de un cuerpo social perdido: aisladas del conjunto del cual formaban parte insinúan un modelo cultural diferente; representan lo que un grupo defiende de su relación presente con un "patrimonio disperso". La afirmación decerteana de la libertad de las prácticas, refrenda una magnánima confianza en una "inteligencia del sujeto" y en la potencialidad del ethos creativo humano. En su obra es deseable una "politización de la pertenencia" donde la tradición aceptada se transformaría en "historia por hacer", en "por-venir" y praxis.
\end{abstract}

Palabras claves: prácticas, vida cotidiana, historicidad, praxis, memoria, ética, antropología.

This article explores the theory of everyday practices in the work of jesuit anthropologist Michel de Certeau. In parallel, it considers the sources upon which it is built: Kant, Marx, Freud, Wittgenstein and Lefebvre, without overlooking the contributions of Foucault and Bourdieu with whom he establishes a fructiferous dialogue. As an anthropological and political urgency, de Certeau posits the reflection on the human practices of habitability and coexistence. A transcendental element of belonging would be located within the practices; traditional making do through which "the collective"-embodying a primeval value of the human species-would remain irreducible to the homogenizing attack of modern society. Everyday practices would remain spread as "memories", combining traces of a lost social body: isolated from the set they used to be part of, hinting a different cultural model; they represent what a group stands for in its present relationship with a "dispersed patrimony". De Certeau's affirmation of freedom of practices endorses a magnanimous confidence in the subject's intelligence and in the potentiality of the creative human ethos. A "politization of belonging" is desirable within his works, where the accepted tradition would be transformed in a "history to do".

Key words: Practices, everyday life, historicity, praxis, memory, ethics, anthropology.

\section{Fuentes para una Historicidad de la Práctica}

El "país de origen" de las prácticas es la vida cotidiana, señala Michel de Certeau (de Certeau 1996:10). La teoría ${ }^{1}$ de tales prácticas -relativas a una cultura "ordinaria" (de Certeau 1996:3)reconoce una deuda íntegra con su pensamiento, sin menoscabar las receptivas contribuciones de su discípula más próxima y prologuista de sus libros, Luce Giard. Según Giard, de Certeau intentó crear un complejo y ambicioso programa investigativo bajo la forma de tres círculos de interlocución. Ella misma fue convocada a la reunión del "primer círculo", en junio de 1974. En una circular, relata
Giard, de Certeau propuso a sus interlocutores una "práctica observadora y comprometida" en un barrio de París. No se trataba de construir "comunidad", sino de abrir "un espacio transitorio por el que se atraviesa y de donde se sale tan amistosamente como se entra" (de Certeau 1996:XXV). Propósito enmarcado en una concepción asombrosamente plural y antidogmática de la praxis antropológica. Los avances de la investigación decerteana fructificaron en el "tercer ciclo de antropología cultural", que el antropólogo impartió en la Universidad París VII. En tal contexto, refiere Giard, de Certeau se preguntaba "cómo entender las actividades de los practicantes; definir un método, describir, comparar y diferenciar actividades por naturaleza subterráneas,

1 Centro de Estudios Latinoamericanos, Facultad de Ciencias Políticas y Sociales, Universidad Nacional Autónoma de México (UNAM), México DF, México. rcassigoli@gmail.com 
efímeras, frágiles y circunstanciales; elaborar a tientas una "ciencia práctica de lo singular" (Giard 1999:XVIII).

Las reflexiones decerteanas condujeron a plantear que el conocimiento de lo particular tendría que ver con la construcción de una cientificidad (de Certeau 1995a:2). ¿Cómo organizar rigurosa y temáticamente esta situación de 'observación participante'? ¿Qué sentido atribuir a las microdiferencias? ¿Cabría imputarlas a diferencias generacionales, tradiciones familiares, hábitos locales, grupos sociales, ideologías, circunstancias? ¿O habría que atribuirlas a regularidades más profundas, ocultas en el secreto de las prácticas? ¿Cómo comprender su multiplicidad? (Giard 1999:XVIII). Una vez formuladas preguntas como estas, según Giard, no se trataba de "soñar" las prácticas, sino de hacerlas inteligibles para que otros pudieran explorar sus operaciones. Tal propósito implicaba un cambio total en la mirada analítica, que debía apoyarse en la puesta en evidencia del orden de los hechos y "hacerse inteligible en el orden de la teoría" (Giard 1999:XVII): "Cada proposición teórica era puesta a prueba de inmediato en una práctica concreta: aquí el andar de la ciudad, allá la descripción de una vivienda, en otra parte la lectura silenciosa" (Giard 1996:XXIV). Para una "ciencia práctica de lo singular", de Certeau sugería, según el relato de Luce Giard, buscar pistas en las obras de Freud y Wittgenstein (Giard 1999:18).

La introducción de Giard a La invención de lo cotidiano. Artes de hacer, constituye la base inicial del presente artículo. En esta obra, las "dilucidaciones filosóficas, hechas bajo el signo de la historia" (Zermeño 1995a:9) emprendidas por de Certeau, constituyen un aporte trascendental a una hermenéutica de la cultura y a una antropología política que discurren sobre la soberanía de la práctica. El antropólogo estudia el universo de las prácticas, con el fin de apuntalar una idea de libertad fincada en la responsabilidad de la acción. Giard refuerza el peculiar legado de de Certeau:

Allí donde el consumismo solo veía consumo pasivo, allí donde el vocabulario marxista hablaba en términos de explotación, masificación y uniformación, Michel de Certeau proponía como primer postulado la actividad creadora de practicantes de lo ordinario (Giard 1999:XVI).
Adicionalmente, la afirmación decerteana de la libertad "montaraz" o arisca de las prácticas (Giard 1996:XXIII), certifica una ilimitada confianza en el prójimo (Giard 1996:XXII) y en la potencialidad del ethos creativo humano. Así, "ninguna condición le aparece a priori como petrificada o desesperante" (Giard 1996:XXI). Dotado de espíritu "anticonformista" y persona "aparte" de la escena intelectual, es como Luce Giard describe a Michel de Certeau: crítico lúcido y exigente "de la epistemología que gobierna en silencio el oficio del historiador" (Giard 1996:XIV). La vigorosa motivación que subyace al proyecto decerteano persigue dilucidar el lugar de la praxis en la investigación antropológica. Inquietud disciplinaria inseparable de una apertura hacia el sentido de autonomía, independencia, e incluso albedrío personal y político. Un albedrío que entraña una política de los sujetos plurales, donde lo político alude a la fuerza de un discenso creativo, más que a la disputa y confrontación representacional en la polis:

Pero de Certeau se esfuerza en disipar todo equívoco respecto a sus intenciones; no quiere proporcionar ni una historia de las teorías sobre las prácticas, ni la constitución de una semiótica [...] Se limita a proponer algunas maneras de pensar las prácticas cotidianas de los consumidores, suponiendo para empezar que son de tipo táctico. Dentro de esta intención, el análisis se ordena en tres niveles: las modalidades de la acción, las formalidades de las prácticas y los tipos de operación especificados por las maneras de hacer (Giard 1996:XXIV).

De acuerdo con de Certeau, la cultura común y cotidiana, concebida como "reapropiación en el consumo", constituye una "manera de practicar" (Giard 1996:XXI). A de Certeau le interesaron las maneras heterogéneas de "marcar socialmente la diferencia producida en un dato a través de la práctica" (Giard 1996: XVIII). El examen de la lógica de la práctica lo condujo al antiguo problema de lo que es un "arte" o una "manera de hacer". Tales maneras de hacer-tradicionales y propias(de Certeau 1995a:209) formarían "repertorios colectivos" reconocibles en los modos particulares del uso de la lengua y el espacio; en las maneras de cocinar y habitar (de Certeau 1995b:49). Desde 
los griegos hasta Durkheim, pasando por Kant, (de Certeau 1996:XLV), explicó de Certeau, una larga tradición se abocó a distinguir "las complejas formalidades que ponen en juego una 'ratio [razón] popular"” (de Certeau 1996:XLV); una "manera de pensar investida de una manera de actuar" (de Certeau 1996:XLV). Provisto de "inteligencias inmemoriales", el hombre común y ordinario, sustentó de Certeau (Giard 1996:XXIII), estaría investido de la capacidad extraordinaria de crear entornos y condiciones electivas mediante prácticas emancipadoras. Los procedimientos de este "arte de hacer" -explicó de Certeau con "inesperado naturalismo aristotélico" (de Certeau 1996:XXIV)-, se remontarían a la lejanía histórica de los seres vivientes; certificarían continuidades y "permanencias de una memoria sin lenguaje, desde el fondo de los océanos hasta las calles de nuestras megalópolis" (de Certeau 1996:47).

Como se aprecia en la revisión de su obra, de Certeau posee la ilustrativa y consecuente cualidad de explicitar sus fuentes investigativas y conceptuales. En su concepción de la práctica como categoría filosófica debe subrayarse, en primer lugar, la influencia de la filosofía marxista de la praxis expuesta en las Tesis sobre Feuerbach. En esta obra, Karl Marx sustentó que "el objeto, la realidad, el mundo sensible" deben ser captados como "actividad humana concreta", "como práctica" (de Certeau 1993:27). En la Tesis XI, Marx consagró "el punto de vista de la práctica en la filosofía". Vale decir, la concepción del mundo como objeto de transformación. Empero, una transformación realizada sobre la base de la interpretación, de la teoría (Sánchez Vázquez 1997:5).

A la par de la inspiración marxista, sin pretender establecer un orden jerárquico, el "arte de pensar" de Immanuel Kant -síntesis entre una reflexión y una "operatividad" (de Certeau 1996:83-87)-, constituyó un segundo antecedente primordial de la teoría decerteana de la práctica (de Certeau 1996:83). El interés kantiano se había dirigido a la relación existente entre el arte de hacer y la ciencia -o entre una técnica y la teoría- en una investigación que, según de Certeau, se desplazó del "gusto" hacia la "crítica del juicio", "colocado en un acto ético y poético" (de Certeau 1996:84). Inspirado en el precepto kantiano, de Certeau abordó el análisis de este "arte genuino y práctico", descartado de los modus operandi científicos (de Certeau 1996:82). Los ejemplos kantianos que interesaron a de Certeau se refieren a un "conocimiento práctico que desborda el conocimiento y tiene forma estética" (de Certeau 1996:83). Gracias a la capacidad de hacer un conjunto nuevo con aquello que preexiste, el conocimiento práctico se aproximaría a la creación artística (de Certeau 1996:84). En la acepción de Levi Strauss, tal noción -evocadora de una "ciencia primera" del bricolage - ilustraría la dimensión práctica del genio humano, capaz de reutilizar inventivamente los objetos y materiales hechos para otros fines (Levi-Strauss 1964:35).

Además de Kant, la obra de Freud constituye una tercera fuente primordial de la antropología decerteana de las prácticas cotidianas; en especial los análisis contenidos en El malestar de la cultura (de Certeau 1996:7). Historia y psicoanálisis se abocó precisamente a tratar la obra de Freud, adicionalmente a la de Lacan y de Foucault: "El psicoanálisis se articula sobre un proceso que es el centro del descubrimiento freudiano: el retorno de lo rechazado (de Certeau 1996:7-8):

Los inmigrados y "minoritarios" nos traen de regreso nuestro propio inconsciente $\mathrm{el}$ cual inhibimos! Al reconocer las economías étnicas bajo la máscara de lo cultural que es el efecto de su rechazo por parte de nuestra historia, contamos con el primer medio para evaluar lo que está en juego" (de Certeau 1995a:201).

Empero, psicoanálisis e historiografía reflexionarían de modo distinto la relación entre el pasado y el presente. El psicoanálisis concibe al pasado alojado en el presente, donde ambos se reproducen recíprocamente mediante la imbricación y la repetición (de Certeau 1995b:78-79). La historiografía, por su parte, colocará al pasado "al lado" del presente, considerando su relación "bajo el modo de la sucesión"; correlación, efecto y disyunción (de Certeau 1995b:79). Las "intervenciones de Freud en la historiografía son casi quirúrgicas", observa de Certeau (de Certeau 1995b:79), y presentan al menos cuatro características:

(1) Disuelven la ruptura entre psicología individual y colectiva; (2) Invalidan la distinción entre normalidad y anormalidad, donde esta última resultaría ser "fenomenal"; (3) Introducen la seguridad de encontrar, en todo lenguaje, "pequeños trozos de 
verdad" cuyo olvido y reminiscencia provocarían posibilidades de cambio en las condiciones presentes y (4) Modifican el "género historiográfico" mediante "la marca de un lugar afectivo, imaginario y simbólico (de Certeau 1995b:81).

La investigación psicoanalítica condujo a las investigaciones etnológicas -antes orientadas hacia una "exterioridad primitiva"- hacia una "interioridad salvaje" de la vida occidental (de Certeau 1995a:201). Se encontraría en el subsuelo de nuestras sociedades la "economía relacional, familiar y colectiva", cuyo lugar pretendería ser ocupado por un "orden productivista e individualista" (de Certeau 1995a:201). Lo que Freud llamó "la escritura de la historia" (de Certeau 1995b:113), se produce "a partir de acontecimientos de los que 'nada' subsiste; ella 'toma el lugar' de los acontecimientos" (de Certeau 1995b:113). He aquí un "desperdicio excluido de lo real" depositado en el proceso de la escritura (de Certeau 1995b:113). La "narrativización de las prácticas" -que en la obra decerteana adquiere la dimensión de una teoría del "relato delincuente" (de Certeau 1996:42)-, representaría entonces una 'manera de hacer' textual con sus procedimientos y tácticas propias (de Certeau 1996:88):

\begin{abstract}
¿No habría que reconocer su legitimidad científica al suponer que en lugar de ser un residuo imposible de eliminar o todavía por eliminar del discurso, la narratividad tiene una función necesaria, y que una teoría del relato es indisociable de una teoría de las prácticas, como su condición al mismo tiempo que como su producción? (de Certeau 1996:88).
\end{abstract}

Además de abrevar en la obra precedente de Marx, Kant y Freud ${ }^{2}$, el pensamiento decerteano se nutre primordialmente de conceptos cruciales que provienen de Wittgenstein, quien recibe "el máximo crédito" (Giard 1996:XXXIII). De acuerdo con Giard, de Certeau heredó de Wittgenstein -a cuya obra se refiere como "diseminada y rigurosa" (de Certeau 1996:18) - el interés por la filosofía del lenguaje ordinario y la dirección ética de su epistemología. Wittgenstein proporcionó "un plano filosófico a una ciencia contemporánea de lo ordinario" (Giard 1996:XXXIII). Particularmente en Tractatus lógicophilosophicus y en Philosophical Investigations, de Wittgenstein (de Certeau 1996:13), de Certeau descubre el análisis del lenguaje "de cada día": se trata de "precisar la morfología del uso de las expresiones", "describir sus formas" y reconocer sus diferentes modos de funcionamiento cotidiano, regidos por reglas pragmáticas que dependen de "formas de vida" (de Certeau 1996:16).

Wittgenstein intenta trazar los límites y desbordamientos del lenguaje desde su interior:

Se trata de abordarlo sin rebasar lo que exceda la competencia de este lenguaje, y por tanto evitar convertirse en el experto, o el intérprete, en otro campo lingüístico (por ejemplo, metafísico o ético), y nunca hablar en otra parte "en su nombre" (de Certeau 1996:13).

Las sintaxis regionales que Wittgenstein examina, “no son tratables en un lugar 'propio', porque el lenguaje no sabría convertirse en el objeto de un discurso" (de Certeau 1996:14): "Estamos sujetos al lenguaje ordinario, aunque no identificados con él" (de Certeau 1996:15). En tal sentido, el análisis "trabaja con lo que muestra sin poder decirlo" (de Certeau 1996:14). Wittgenstein, según de Certeau, "se ha fijado como tarea ser el científico de la actividad significante en el lenguaje común" (de Certeau 1996:13):

Muy rara vez la realidad del lenguaje ha sido tan rigurosamente tomada en serio, es decir, el hecho de que esta define nuestra historicidad, que nos domina y envuelve bajo el modo de lo ordinario, que ningún discurso puede entonces "salirse" y colocarse a distancia para observarlo y expresar su sentido (de Certeau 1996:14).

Wittgenstein, recapituló de Certeau, rechazaría la historiografía por separar el presente del pasado "privilegiando un lugar propio", desde donde pretendería "dominar los actos de la lengua" (de Certeau 1996:14). Aun cuando las experiencias humanas "no pueden reducirse a lo que se dice de ellas, las cientificidades se permiten olvidarlas para constituirse y las filosofías creen dominarlas para autorizarse a tratarlas" (de Certeau 1996:15). Por último, es importante recalcar la huella de Wittgenstein en la obra decerteana, distinguiendo la atención prestada a los fragmentos: "(Wittgenstein 
ha querido que su obra misma esté compuesta solo por fragmentos), inscritos en una textura donde cada uno puede a veces 'hacer un llamado' a la otra instancia, citarla y referirse a ella" (de Certeau 1996:15).

Por último, en referencia a otras fuentes inspiradoras, los legados de Michel Foucault y de Pierre Bourdieu, con cuyas obras dialoga, representaron para de Certeau "dos monumentos" de una "manera de hacer" la teoría de las prácticas (de Certeau 1996:53). De acuerdo con Giard, de Certeau planteó cuestiones análogas a las expuestas en el libro de Foucault Vigilar y castigar. Vislumbró la proliferación de "operaciones microbianas" al interior de las "estructuras tecnocráticas", capaces de modificar su funcionamiento mediante detalles cotidianos (Giard 1996:XVIII). A lo largo de toda su obra, expone la autora, de Certeau propone "prácticas transgresoras de las organizaciones funcionalistas, ajenas al espacio geométrico y geográfico de las construcciones visuales panópticas" (de Certeau 1996:108). Se refiere, al parecer, a prácticas adscritas al universo de la capacidad inventiva, la imaginación y la creación, que permitirían trascender los referidos límites geométricos y geográficos que la planificación instrumental impone (de Certeau 1996:105). El desarrollo "canceroso" de los dispositivos panópticos se constituye históricamente en un arma para combatir prácticas culturales heterogéneas. Bajo el "monoteísmo" resultante del privilegio de estos dispositivos, sobreviviría un "politeísmo" de prácticas "diseminadas" (de Certeau 1996:56-57). A través de sus prácticas, las alteridades sociales, resistentes al comportamiento caníbal (de Certeau 1993:333) del panoptismo, asumen ahora el más relevante papel de transgredir la transparencia:

En nuestros países lo opaco se vuelve necesario, se funda sobre los derechos de una comunidad, susceptibles de equilibrar la economía que en nombre de los derechos individuales, expone toda la realidad social a la luz universal del mercado y la administración (de Certeau 1995a:205).

Según Giard, a diferencia de Foucault y Bourdieu -que hicieron énfasis en el modo en que la "violencia del orden se transforma en tecnología disciplinaria"-, de Certeau se interesó en los "ardides"3 de los consumidores, mismos "que componen, finalmente, el ambiente de antidisciplina" que caracteriza a $L a$ invención de lo cotidiano (Giard 1996:XXI). Una práctica de tales ardides -enraizados en inteligencias y astucias inmemoriales de insectos proteicos, plantas y peces- subsiste "en las zonas literarias donde ha sido rechazada" (de Certeau 1996:XLI).

El "escamoteo" 4 reintroduce, mediante una resistencia práctica, las maneras "populares de antaño" o "de otra parte" en el presente industrial (de Certeau 1996:31). Las prácticas ordinarias -en cuya inteligencia subjetiva de Certeau distingue los recursos infinitos de una "resistencia silenciosa y a veces desesperada" de los débiles (Giard 1995:14)-, "pululan" tomando la forma de lo que no habla: infans, del latín, incapaz de hablar (de Certeau 1996:59). Escribe, con bien encauzada certeza: "Hay que volverse de cara a estas prácticas, a aquella proliferación diseminada de creaciones anónimas y perecederas, que no se capitalizan pero hacen vivir" (de Certeau 1996:18).

De Certeau propuso en su obra, analizar estas maneras de hacer "microbianas, singulares y plurales, que sobreviven a la decadencia del sistema urbanístico y se refuerzan en una ilegitimidad proliferadora" (de Certeau 1996:108). En "el espacio tecnocráticamente construido, escrito y funcionalista donde circulan los consumidores", las trayectorias de los transeúntes formarían "frases imprevisibles para trazar otros deseos" (de Certeau 1996:XLIX). Frases que, pese a tener como material los "vocabularios recibidos encuadrados en sintaxis prescritas", constituyen "atajos" heterogéneos en los sistemas donde se infiltran, para perseguir intereses y astucias diferentes (de Certeau 1996:41). Tales prácticas microbianas y plurales -concebidas como actos de enunciaciónequivalen a "huellas de pasos" y trayectorias que revelarían operaciones de las que han sido objeto.

Las prácticas describen una "trayectoria". Ella evoca un movimiento que consiste en una transcripción. Vale decir, explicó el autor, en una "grafía" (que el ojo puede dominar) que sustituyó a una operación. Una huella que reemplazó a unos actos" (de Certeau 1996: XLIX). La actividad de los transeúntes haría invisible, según de Certeau, la acción que la hizo posible: "son los procedimientos del olvido" (de Certeau 1996:109). Al sustituir a la práctica, la huella manifestaría una propiedad del sistema geográfico, la de metamorfosear la acción para hacerla legible: "pero la huella hace olvidar una manera de ser en el mundo" (de Certeau 1996:109).

Si bien la problemática de la enunciación se refiere al acto del habla -mediante el cual "un 
locutor actualiza la lengua y se apropia de ella en una situación particular de intercambio o de contrato" (de Certeau 1996:105)-, de acuerdo con de Certeau esta problemática podría ampliarse al conjunto de la cultura "en razón de las similitudes entre los procedimientos (enunciativos) que articulan las intervenciones, tanto en el campo de la lengua, como en el tejido de las prácticas sociales" (de Certeau 1996:105).

Las "huellas de actos" le parecieron a de Certeau indicios de una "historicidad de la práctica", así como una "historicidad de la historia" implicaría un movimiento que vincula una práctica interpretativa con una praxis social (de Certeau 1993:35). Tal historicidad, en resumidas cuentas, involucraría la existencia de una mediación o "manipulación" de los usuarios de los sistemas de representaciones, que dejarían de figurar ya como cuadros normativos (de Certeau 1996:26): "Algo esencial se halla en juego en la existencia de los sujetos que son los actores y autores de sus prácticas" (de Certeau 1996:25). La referida historicidad de la práctica se traduciría en "la capacidad de un grupo para transformarse a sí mismo; la manera en que una colectividad humana es un sujeto de su historia y no solo un producto de sus presiones" (de Certeau 1995a:211).

La verdadera pregunta que Michel de Certeau se formula, escribe Luce Giard, la pregunta "indiscreta" es: “¿Cómo crearse?”. Pregunta que desplazó a aquella que, hasta entonces, había manifestado una "urgencia imperiosa": “¿crear qué y cómo?" (Giard 1996:XVII). Esta suerte de autointerpelación constituye quizá el rasgo más asombroso de la filosofía política decerteana. Como bien explica Giard, refleja el cambio total de perspectiva que fundará La invención de lo cotidiano, al desplazar la atención del consumo pasivo de productos recibidos, a la creación anónima con base en ellos. Vale decir, a la "práctica de desviación en el uso", noción recalcada desde Kant (Giard 1996:XVII). Cabría preguntarse lo que el consumidor fabrica con las imágenes; "enigma del consumidor esfinge" (de Certeau 1996:37). El consumo tiene como característica sus "cacerías furtivas, su clandestinidad, su murmullo incansable" (de Certeau 1996:22) y se distingue, más que por sus productos propios, por el arte de utilizar los que le son impuestos (de Certeau 1996:38): "Por lo general, una manera de utilizar los sistemas impuestos constituye la resistencia a la ley histórica de un estado de hecho y a sus legitimaciones dogmáticas” (de Certeau 1996:22).

\section{Prácticas sin Discurso}

Michel de Certeau plantea el problema de la relación de las prácticas con el discurso. En su obra, la distinción no se refiere ya al binomio tradicional "teoría y práctica", sino a dos operaciones diferentes: una discursiva y otra sin discurso. Se trataría de distinguir entre prácticas articuladas en discursos y prácticas que no lo están. El problema, para de Certeau, se plantea cuando "en lugar de ser un discurso sobre otros discursos, la teoría debe aventurarse sobre una región donde ya no hay discursos: falta el suelo al lenguaje verbal" (de Certeau 1996:71). Foucault y Bourdieu, manifiesta de Certeau, situaron su empresa en este borde, al articular un discurso sobre prácticas no discursivas: "las prácticas no poseen la fijeza repetitiva de ritos, costumbres o reflejos, conocimientos que todavía no se articulan en discursos" (de Certeau 1996:53). La "pululación" y "proliferación" de lo que "no habla" tiene, entre otras, la forma de "prácticas ordinarias". Foucault habría intentado articular en el lenguaje tal "politeísmo de prácticas diseminadas" (de Certeau 1996:57):

multiplica los sinónimos, las palabras danzantes, las aproximaciones sucesivas de un imposible nombre propio; [empero], la incertidumbre y la agitación de la cosa en el lenguaje constituyen ya un signo (de Certeau 1996:53).

Las prácticas ordinarias no discursivas entrañarían una "desviación en el uso". En la obra de Kant -haciendo una paráfrasis del texto decerteanoun conocimiento práctico que desborda el propio conocimiento, tiene forma estética. Es un "arte de hacer", emplazado bajo el signo del "juicio"o "sentido común" (de Certeau 1996:84). Desde el propio Kant, apuntó de Certeau, toda investigación teórica ha debido explicar su relación con esta "actividad sin discurso", con este "resto inmenso constituido por lo que, de la experiencia humana, no ha sido "domesticado ni simbolizado dentro del lenguaje" (de Certeau 1996:71). La "optimización técnica" del siglo XIX confinó las prácticas cotidianas al espacio privado. A partir de la revolución industrial, ellas permanecerían confinadas "en una región folclórica, o bien en una tierra silenciosa por partida doble: sin discurso verbal como antaño y en adelante sin lenguaje maniobrero" (de Certeau 1996:80). 
En la obra de Pierre Bourdieu, el "sentido común", habitus o racionalidad práctica, se dirigió vigorosamente a modular un discurso sobre las prácticas no discursivas, designadas como “estrategias" (de Certeau 1996:61). Lo que la teoría excluye de ella misma, "pulula" en su interior impidiendo que se constituya el sentido (de Certeau 1996:66). En esta concepción, la práctica "organiza discontinuidades, nudos de operaciones heterogéneas" (de Certeau 1996:62). Sin embargo, en los casos que examinó Bourdieu -el sistema sucesorio del Bearn, en los Pirineos, y la disposición interior de la casa de Cabilia, en Argelia- se pueden especificar propiedades de una "lógica de la práctica" (de Certeau 1996:61). El discurso condujo a Bourdieu hacia el habitus (de Certeau 1996:66-51), cuyos sinónimos exis, ethos, modus operandi, "sentido común" o "segunda naturaleza" (de Certeau 1996:66-67), apuntaban a descifrar cómo se generan y en qué se fundamentan las prácticas.

Lo que interesó a los antropólogos de la obra de Bourdieu, es la supresión teórica de la distancia entre las "legalidades" de la sociología y las "particularidades" etnológicas (de Certeau 1996:61): el análisis de las prácticas particulares por un lado, y por el otro el papel que se les asigna en la construcción de una teoría (de Certeau 1996:61). La casa ${ }^{5}$, forma material que en la obra de Bourdieu adquiere el habitus, está concebida por este último, según de Certeau, como un fragmento, "una forma particular y aislada", que deviene receptáculo de la práctica y referencia a toda metáfora. Su estudio fue considerado por Bourdieu, dice el autor, "como ilegal a la luz de una normatividad de la disciplina" actuando "demasiado con la gama simbólica, en suma es un lapsus" (de Certeau 1996:61).

La contribución particular de Michel de Certeau, apuntó a distinguir la extraña disparidad existente entre el tratamiento de las prácticas y el de los discursos: "Ahí donde primero se registra una 'verdad del hacer', en el otro se descifra las "mentiras del decir"' (de Certeau 1996:77-78). Las prácticas ordinarias no discursivas permanecerían desterradas del relato historiográfico y construcción del conocimiento. Al ser consideradas como "banales" (Lefebvre 1972:22) para la teoría, adoptarían la forma de resistencias. A las prácticas sin discurso de Certeau les asigna el papel, determinante para la teoría, de constituir "reservas salvajes para el conocimiento ilustrado" (de Certeau 1996:74). En los "talleres" artesanales del inconsciente, yace un conocimiento fundamental y primitivo que se adelanta al discurso ilustrado, pero al cual le falta una cultura propia: "docta ignorancia" (de Certeau 1996:58).

La generalización de la "racionalidad" -paradigma práctico del cuerpo político moderno-ha provocado, según de Certeau, un desmoronamiento de las prácticas antes reguladas por unidades locales estables. Al no estar fijadas en una comunidad delimitada, las prácticas "se desorbitan" (de Certeau 1996:L). Separadas de sus comunidades tradicionales vagan por doquier en un espacio homogéneo: los consumidores se convierten en migrantes (de Certeau 1996:47). Michel de Certeau se interesó por las prácticas de los inmigrantes que "alojan regímenes heterogéneos de convivencia en sitios distintos" (de Certeau 1995a:197). Las prácticas migrantes "habitan nuestros terrenos epistemológicos" (de Certeau 1995a:197):

La economía inmigrante hace entrar en nuestro campo esta economía táctica. Los procedimientos ayer expulsados se implantan en el interior de lo que hacemos del espacio donde habitamos. Es a estas prácticas, a su arte, a sus combinaciones, a las que hay que otorgar el derecho y los medios para ejercerse en las maneras de habitar, soñar, aprender (de Certeau 1995a:219).

\section{Praxis de la Memoria}

Las prácticas cotidianas permanecen esparcidas como "memorias". Combinan, en la visión decerteana, rastros de un cuerpo social perdido: aisladas del conjunto del cual formaban parte insinúan un "modelo cultural diferente" (de Certeau 1995a:222). La figura del migrante, o el "minoritario", exacerba el paradigma de la resistencia a la asimilación cultural. El alejamiento de las bases referentes, la adopción obligatoria de códigos administrativos y habituación a un nuevo espacio, se traducen en toda una gama de tácticas o maneras de reutilizar con fines propios el orden impuesto y arbitrario de las cosas. Muestran una creatividad sin límites en sus capacidades: "Las comunidades híbridas, cuya representación se encuentra enmascarada en nuestra escena nacional por los efectos de una asimilación, se han transformado también por su ajuste a situaciones inéditas, es decir por los 
efectos de una adaptación" (de Certeau 1995a:207). Los "extranjeros" personificarían y proveerían el ángulo visual crítico; ya que no solo rechazan una identidad impuesta por la sociedad dominante, sino la misma idea de identidad, "desde el momento en que reivindican el derecho de ser ellos mismos y construir su camino en medio de la diversidad" (de Certeau 1995a:195).

Es en las prácticas ordinarias de aquellos "minoritarios" donde lo colectivo permanece irreductible (de Certeau 1995a:209). Sus "maneras de hacer" aglutinarían procedimientos de orígenes heterogéneos. Ellos se cruzarían en las actividades individuales que reintroducen derechos colectivos en las "administraciones jurídicas, económicas, escolares" (de Certeau 1995a:200). El carácter de estas maneras no es totalizador, explicó de Certeau, ellas no forman parte de conjuntos coherentes (de Certeau 1995b:50). Encarnan, en la visión decerteana, fragmentos de memoria; representarían lo que un grupo defiende de su "relación presente con un patrimonio disperso" (de Certeau 1995a:223):

Insertos en prácticas, latentes y diseminados como estatuillas familiares que en el pasado se colocaban en los rincones de las casas, espíritus silenciosos del lugar pero 'espíritus' que solo son detalles materiales, tienen de particular que ya no organizan más la vida social, profesional, administrativa o familiar; la puntúan de marcas aparentemente insignificantes y pese a todo decisivas. Esta tradición sigue siendo determinante pero a la manera de fragmentos relativos a sistemas derrumbados o abandonados. Son significantes de ya no se sabe qué (de Certeau 1995a:222).

Es en virtud de estos fragmentos de memoria, que se conserva testaruda, despedazada y muda, libre de todo dominio, una alteridad étnica. Concebida como praxis, la memoria no se limita al pasado, sino que concierne a la responsabilidad presente. Una forma de pertenencia "gravada en las prácticas sociales a manera de joya familiar sin valor" (de Certeau 1995a:222) -que existe en calidad de reliquia aparentemente trivial-, trae al campo de lo conocido las "irrupciones" (de Certeau 1995a:223). Parecen imponerse, aquí, dos concepciones de la memoria enlazadas con la praxis. La primera referida a una afirmación subjetiva y plural de la pertenencia; la segunda representada por el carácter irruptivo en el cual la memoria toma la forma de una acción que produce significado. Ya que tales "memorias" reflejan auténticos "desplazamientos" de costumbres, que ya no se benefician de un lenguaje propio que los simbolice: "están como dormidas, su sueño sin embargo solo es aparente. Si se tocan, se desatan violencias imprevisibles" (de Certeau 1995a:222).

De Certeau se preguntó bajo qué figuras enmascaradas reaparecen los derechos de las colectividades; qué formas adquiere la "pertenencia" (de Certeau 1995a:200). El sentido primordial de pertenencia de los "sujetos sociales" emana de una dialéctica entre el hombre y sus prácticas de espacio. La práctica asocia el "arte del hacer", con los combates del vivir (de Certeau 1995:218), lo cual corresponde a la naturaleza misma de la práctica. La "politización de la pertenencia" encarnaría, en la obra decerteana, la ya mencionada "ruptura instauradora", donde la tradición aceptada se transforma en "historia por hacer" (de Certeau 1995a:209). Asimismo, se transforma en una praxis que no se limita al pasado, sino que prevé las "vías múltiples del porvenir" (de Certeau 1996:93). Michel de Certeau afianza, en este postulado, una concepción ética de la práctica y al mismo tiempo, una concepción práctica de la ética bajo la forma de resistencia (Giard 1996:XXIV). En el "hacer cotidiano", radicaría, en el pensamiento decerteano, una clave inexplorada para la apertura hacia el sentido de la emancipación personal y política.

Las costumbres esparcidas y tenaces, reflexionó, entrañan una irreductibilidad colectiva; emplazan, con obligación antropológica y política, el abordaje de las prácticas humanas de la habitabilidad y la convivencia (de Certeau 1995a:227). Ya no se tratará, cifra nuestro autor en su libro de antropología política La toma de la palabra y otros escritos políticos, "de expresar subjetividades, sino de emprender trabajos prácticos de convivencia" (de Certeau 1995a:227).

\section{Conclusiones. La Idea de Praxis de Lefebvre a De Certeau}

El significado del término "político", en el pensamiento decerteano, no puede adjudicarse sino al sentido de praxis. Lo cual debe hacerse desde el más estricto principio de pluralidad y respeto a la libertad del interlocutor. Parecen urgentes una acción y una reflexión: 
Hay que reconocerse diferentes (de una diferencia que no puede superarse mediante ninguna posición magisterial, mediante ningún determinado discurso, mediante ningún fervor festivo) para que un seminario se transforme en una historia común y parcial (un trabajo sobre las diferencias y entre ellas) y para que el habla se transforme ahí en el instrumento de una política (de Certeau 1995:19).

Las investigaciones de Henri Lefebvre, en especial La vida cotidiana en el mundo moderno (Lefebvre 1972), constituyen la fuente esencial que precede la acepción decerteana del concepto de praxis. Al mismo tiempo que se impulsaba el movimiento de la "imaginación al poder", el 68 francés, Lefebvre vislumbraba la "irrupción de lo cotidiano" en la literatura de Balzac, Flaubert, Zola (Lefebvre 1972:9). A la par de un flanco literario de lo cotidiano, las reflexiones de Lefebvre y Michel de Certeau buscaron robustecer el sesgo filosófico y antropológico 6 . Para Lefebvre el vocablo "cotidiano" poseía un matiz alienado y rutinario "acompañado de su negación por el sueño, por lo imaginario, por el simbolismo; negación que supone también la ironía frente a los símbolos y lo imaginario" (Lefebvre 1972:9). Michel de Certeau, sin embargo, descubrirá en el terreno de lo cotidiano la vía de transformación de las prácticas, guiada por un interés emancipador sostenido en la "llama de una exigencia" ética (Giard 1995a:16).

Asimismo, la afirmación de la pluralidad del sentido y su coexistencia, presentes en la concepción decerteana, constituye una herencia que ha recorrido transversalmente la obra precedente e iluminadora de Henri Lefebvre (Lefebvre 1972:9). Como también la crítica al "carácter literal propiamente escriturario" (Lefebvre 1972:12) que inspiraría, en Michel de Certeau, su brillante epítome $L a$ escritura de la Historia (de Certeau 1993). La problemática del devenir heraclitiano -el gran río en que nada es lineal-, el "tiempo cíclico, el tiempo vivido, cotidiano y cósmico" y la problemática del habla, se encuentran vivamente prefiguradas en la obra fundamental de Lefebvre (1972:12-13). En su concepción, la vida cotidiana se presenta, en relación con la filosofía, como no filosófica; es decir, como "mundo real" en relación "al ideal" (Lefebvre 1972:21): "Donde se goza o se sufre es en lo cotidiano" (Lefebvre 1972:32).
Lefebvre explicitó la tendencia del discurso cientificista -prevaleciente en las humanidades-a excluir la experiencia cotidiana: "Frente a la vida cotidiana, la vida filosófica se pretende superior y se descubre como vida abstracta y ausente, distanciada, separada" (Lefebvre 1972:22). Se opuso a considerar lo cotidiano -humilde y en apariencia insignificante-(Lefebvre 1972:36) como un "desechado". Espoleará el rescate de la práctica de su lugar "banal" (Lefebvre 1972:22). Según Lefebvre, describir y analizar lo cotidiano, a partir de la filosofía, implicaba "el proyecto revolucionario de una liberación que desgaje de lo cotidiano la actividad creadora inherente, la obra inacabada" (Lefebvre 1972:22): "Lo cotidiano es lo que no lleva fecha. Es lo insignificante (aparentemente) ¿No es lo cotidiano la suma de las insignificancias?" (Lefebvre 1972:39).

De la obra de Henri Lefebvre, Michel de Certeau heredó seguramente la nostalgia del estilo que antaño marcaba los detalles. Espíritu de una genuina poética de la cual nos provee "gestos, palabras, instrumentos, objetos familiares no habían caído todavía en la prosa del mundo" (Lefebvre 1972:42). Empero, posiblemente el rasgo más determinante que la obra de Lefevbre brindó a de Certeau, es la concepción de la praxis como núcleo racional de la vida cotidiana; así como la cultura es también una praxis (Lefebvre 1972:45). En el ámbito de una "sociología de la crisis", Lefebvre figuró como el único que anunció -allende el "situacionismo"- una sociología del cambio (de Certeau 1995a:103-104). En Francia, Lefebvre hizo eco, hasta 1958 -año en que es expulsado del Partido Comunista- de los postulados de la escuela de Frankfurt, en el sentido de que el único modo digno de ser del marxismo, es asumir radicalmente su carácter de crítica. Sobre todo, de crítica práctica. El marxismo debe ser "autocrítico"; debe criticar su propia praxis (Sabiote 1983:267). Fueron los descubrimientos y descripciones de Lefebvre sobre la vida cotidiana, en resumidas cuentas, la fuente principal de las investigaciones decerteanas sobre la praxis gregaria. Ilustra Luce Giard:

Michel de Certeau creía en el duro trabajo de emancipación que cada uno debería realizar en sí mismo, por cuenta propia, en la soledad, a fin de sacar a luz la exigencia ética que habría de gobernar su vida, en el orden de lo visible y lo invisible; es decir, 
para volverse capaz de tomar una parte de responsabilidad en la edificación del cuerpo social (Giard 1995a:15).

Desde los turbios años de la postguerra, relata Giard, de Certeau había conservado una certeza: "nadie puede sustraerse de la esfera pública, pues nadie puede eludir su parte de responsabilidad política en lo que es el combate de todos" (Giard 1995a:15). De Certeau sabía que "el trabajo de emancipación llevaba una dolorosa fase de desgarramiento, de alejamiento de certezas previas, a veces de una ruptura sin retorno" (Giard 1995a:15).

El ensueño político decerteano desearía interponerse en el orden utilitario del mundo; en la "utopía tecnocrática e higiénica que funciona en un vacío de posibilidades humanas", que describió magistralmente George Steiner (Steiner 1992:96). Lo haría mediante pequeñas rutinas populares que de Certeau rescata a modo de "maneras" minúsculas y habituales que "juegan" con los mecanismos disciplinarios para cambiarlos. Corresponden a procedimientos de la creatividad ordinaria, "dispersa, táctica y artesanal de grupos e individuos atrapados dentro de las redes de la vigilancia" (de Certeau 1996:105). Una "extrañeza de lo cotidiano no sale a la superficie"; aflora en la práctica gregaria por obra de una "inteligencia del sujeto" (de Certeau 1996:82). En la medida en que la práctica ha permanecido gradualmente "disociada de las técnicas y lenguajes que la objetivaban", ha experimentado una sutil metamorfosis: se ha configurado como conocimiento intrínseco, síntesis entre el tacto, el juicio, el gusto y el instinto (de Certeau 1996:82).

Michel de Certeau abrigó una ilimitada confianza en este "prójimo" (de Certeau 1996:121), en el talento intangible del más débil, desposeído de un lugar propio, "desprovisto ante las estrategias del fuerte, propietario del teatro de operaciones" (Giard 1996:XXIV). Las tácticas del consumo -concebidas en el contexto de la obra decerteana como "ingeniosidades del débil para sacar ventaja del fuerte"-, derivarán en una "politización de las prácticas cotidianas" (de Certeau 1996:XLVIII). Dentro de esta confianza en la inventividad del "débil", se dibuja ya, recapitula Giard, una "concepción política del actuar"; una concepción de la relación inequitativa existente entre el poder y los sujetos (Giard 1996:XXIV): "Por perder su sitio el individuo nace como sujeto" (de Certeau 1996:151). A Giard le parece reconocer aquí, "la huella de una concepción ignaciana del hacer" (Giard 1996:XXIV). Característicamente, en Michel de Certeau, la concepción del hacer es inseparable de la referencia a un "arte" y a un "estilo"; "dos nociones igualmente propias de la cultura jesuítica del Renacimiento" (Giard 1996:XXIV). Ambas nociones, explica Giard, le sirvieron para comprender las prácticas culturales como un "estilo de resistencia moral" (Giard 1996:XXIV).

Las "prácticas del espacio" remitirían, según de Certeau, a "otra espacialidad"; a una "experiencia antropológica, poética y mítica del espacio" (de Certeau 1996:105). Declaración intuitiva que parece condensar el carácter poético de la antropología decerteana: una poética que impide la producción cerrada, por decirlo de algún modo, de la teoría (de Certeau 1996:164). La magnífica expresión "ruptura instauradora", desea describir lo que puede experimentar un viajero ordinario cuando se encuentra en lugares de tránsito. Una "extrañeza del etnólogo" que sugiere la configuración imaginaria de una "ciudad trashumante y metafórica", asomada en el "texto vivo de la ciudad planificada y legible [...] cada paso es irrepetible, pertenece a lo cualitativo" (de Certeau 1996:105).

De Certeau distingue las "mil maneras" (de Certeau 1996:35) de habitar un espacio, específicas de una comunidad. Capaces de "mantenerse incluso allí donde han cambiado las condiciones objetivas del hábitat. Al agregarse, permiten la 'apropiación del nuevo paisaje"” (de Certeau 1995a:218). Sin duda, escribió, "hay umbrales más allá de los cuales estas prácticas se desmoronan, al ceder poco a poco a los usos propios de una nueva pertenencia" (de Certeau 1995a:219). Se trata de "prácticas inasimilables que entrañan una especificidad" que se introducen e implantan en el espacio donde habitamos (de Certeau 1995a:220). De Certeau esbozó tres modos de abordamiento e investigación de las prácticas. El primero apunta a la observación de prácticas ordinarias (hablar, habitar, caminar, leer, enseñar); el segundo a la extensión del análisis de estas prácticas cotidianas a sectores científicos regidos por otro tipo de lógica; y el tercero a la observación de "huellas de actos" que forman "frases imprevisibles" (de Certeau 1996:XLVIII). Permanecen realzadas aquí, en resumidas cuentas, tres herramientas inherentes al método antropológico: la observación cualitativa, la autorreflexión de la praxis por parte del investigador plural, y la aforística "aprehensión poética del objeto" legada por Lévi-Strauss (1971:9). 
Agradecimientos: Al programa de Apoyos para la Superación Académica de la Universidad Nacional Autónoma de México. A Santiago Derbez por su lectura exigente y precisa. A los lectores y dictaminadores que tuvieron a bien brindar valiosas sugerencias.

\section{Referencias Citadas}

De Certeau, M. 1995a. La Toma de la Palabra y Otros Escritos Políticos. Universidad Iberoamericana, Instituto Tecnológico y de Estudios Superiores de Occidente, México, D.F.

De Certeau, M. 1995b. Historia y Psicoanálisis. Universidad Iberoamericana, Instituto Tecnológico y de Estudios Superiores de Occidente, México, D.F.

De Certeau, M. 1996a. La Invención de lo Cotidiano. 1 Artes de Hacer. Universidad Iberoamericana, Instituto Tecnológico y de Estudios Superiores de Occidente, Centro Francés de Estudios Mexicanos y Centroamericanos, México, D.F.

De Certeau, M. 1996b. La Invención de lo Cotidiano 2. Habitar, Cocinar. Universidad Iberoamericana, Instituto Tecnológico y de Estudios Superiores de Occidente, México, D.F.

Giannini, H. 1987. La Reflexión Cotidiana. Hacia una Arqueología de la Experiencia. Editorial Universitaria, Santiago.

Giard, L. 1996. Historia de una investigación. En La Invención de lo Cotidiano 2. Habitar, Cocinar, editado por M. De Certeau, L. Giard y P. Mayol, pp. 6-7. Universidad Iberoamericana, Instituto Tecnológico y de Estudios Superiores de Occidente, México, D.F.

Giard, L. 1995a. Porqué el mañana ya se dispone a nacer. En La Toma de la Palabra y Otros Escritos Políticos, editado por M. De Certeau, pp. 4-9. Universidad Iberoamericana, Instituto Tecnológico y de Estudios Superiores de Occidente, México, D.F.

Giard, L. 1999. Momentos y lugares. En La Invención de lo Cotidiano 2. Habitar, Cocinar, editado por M. De Certeau,
L. Giard y P. Mayol, p. XVIII. Universidad Iberoamericana, Instituto Tecnológico y de Estudios Superiores de Occidente, México, D.F.

Lefebvre, H. 1972. La Vida Cotidiana en el Mundo Moderno. Alianza Editorial, Madrid.

Lévi-Strauss, C. 1964. El Pensamiento Salvaje. Fondo de Cultura Económica, México, D.F.

Lévi-Strauss, C. 1971. Arte, Lenguaje y Etnología. Entrevistas con George Charbonnier. Siglo XXI, México, D.F.

Mayol, P. 1999. Habitar. En La Invención de lo Cotidiano 2. Habitar, Cocinar, editado por M. De Certeau, L. Giard y P. Mayol, pp. 6-7. Universidad Iberoamericana, Instituto Tecnológico y de Estudios Superiores de Occidente, México, D.F.

Sabiote, D. 1983. El Problema del Humanismo en E. Fromm y H. Marcuse. Publicaciones Universidad Pontificia de Salamanca, Salamanca.

Sánchez Vázquez, A. 1977. La filosofía de la praxis como nueva práctica de la filosofía. Cuadernos Políticos 12:64-68.

Steiner, G.1992. En el Castillo de Barba Azul. Aproximación a un Nuevo Concepto de Cultura. Gedisa, Barcelona.

Zermeño, G. 1995. Prefacio. En La Toma de la Palabra y Otros Escritos Políticos, editado por M. De Certeau, pp. 9-10. Universidad Iberoamericana, Instituto Tecnológico y de Estudios Superiores de Occidente, México, D.F.

\section{Notas}

1 De Certeau conserva la significación antigua en la palabra teoría: "ver/hacer ver" o contemplar, en griego (de Certeau 1996:82).

2 Perteneció a la escuela freudiana de Jacques Lacan desde su fundación en 1964 y hasta su disolución en 1980: "El psicoanálisis lo atraía cada vez más como procedimiento de dilucidación personal y como crítica teórica de la sociedad" (Giard 1995:16).

3 Los "ardides tácticos y retóricos" están condenados a la ilegitimidad, por parte de la "familia científica" (de Certeau 1996:58).
4 El "escamoteo" como "modelo operativo de una cultura popular" (de Certeau 1996:30).

5 Sobre la noción de "casa" de Certeau sugiere revisar el concepto en los cursos impartidos por Claude Levi-Strauss de los años 1976-1982 (de Certeau 1995a:199). Ver también La notion de maison. Entretien avec Lévi-Strauss par Pierre Lamaison, Terrain. Revue d'ethnologie de la France, 9 octobre, 1987.

6 Interesa marcadamente la reflexión sobre lo cotidiano que emprendió y practicó el filósofo chileno Humberto Giannini, en su obra La reflexión cotidiana, hacia una arqueología de la experiencia (Giannini 1987). 
